available on the internet

(www.blackhealthagency.org.uk/drupal/vid eo) or can be ordered as a DVD from the Black Health Agency at cost price. Copies have already been requested by agencies as diverse as refugee community organisations, Citizens Advice Bureaux, and tutors of English as a foreign language, as well as health organisations. We believe that going beyond traditional healthcare organisations is the key to getting information out to the people who need it most.

A qualitative evaluation of the film was overwhelmingly positive and provided useful feedback on how it could best be used, in combination with information on local services. GPs working in areas with high numbers of new immigrants, asylum seekers or otherwise, might like to direct their new patients to the film in order to ease their transition into the NHS.

\section{Pip Fisher,}

GP \& Tutor to Refugee Doctors, Whitehouse Centre, 23 New North Parade, Huddersfield HD1 5UJ. E-mail: pipfisher@btopenworld.com

\section{REFERENCE}

1. O'Donnell CA, Higgins M, Chauhan R, et al. Asylum seekers' expectations of and trust in general practice: a qualitative study. Br J Gen Pract 2008; 58(557): 870-876.

DOI: 10.3399/bjgp09X420374

\section{Diabetic feet}

In their recent publication 'Patients' perspectives on foot complications in type 2 diabetes: a qualitative study', Gale and colleagues highlight the discrepancies between clinicians' and patients' views of diabetic foot complications. The authors state that 'this particular study is, to the authors' knowledge, the first to investigate perceptions of foot complications among people with type 2 diabetes who do not have personal experience of ulceration."

We would point out that this topic has been extensively investigated by our group using both qualitative and quantitative methods and that our studies included both patients with and without previous foot ulceration. The findings of this large Diabetes UK- and American Diabetes Association-funded study have been described in a number of publications. ${ }^{2-4}$

The combination of patient interviews with our clinical experience informed the development of the Patient Interpretation of Neuropathy (PIN) questionnaire, an instrument assessing patients' commonsense misperceptions about diabetic foot complications, their levels of understanding of foot problem-related medical information, and foot problemspecific emotional responses that are associated with foot self-care. ${ }^{4}$ The 39 item PIN fully covers the themes described by Gale et al; such as, the vascular model of foot complications (PIN: 'good circulation in the feet means that a person will not get foot ulcers on their feet'), ${ }^{4}$ which leads to the engagement in ineffective foot care (PIN: 'Engaging in activities such as walking or massaging my feet can improve circulation in my feet'); ${ }^{4}$ or dissatisfaction with practitioners (PIN: 'I feel angry about healthcare providers not telling me what is really going on with my feet'). ${ }^{4}$ Additionally, the PIN assesses a number of patient misperceptions that are not described in Gale's study including those that are shaped by neuropathy-related peripheral insensitivity. These, for example, include the belief that the development or worsening of foot ulcers would be accompanied by pain. Importantly, the PIN provides the coverage of one of the most important determinants of foot selfcare; that is, patient understanding of ulcer causes with a focus on the intrinsic risks (for example, hard skin formation), as our interviews demonstrated that patients lack understanding about the causal links between diabetes-related nerve damage and ulceration.

The PIN has been validated in a sample of 495 patients at risk of foot ulceration (64\% no personal experience with ulcers). It showed good ability in discriminating between those with and without foot ulceration and a strong relationship with foot self-care.
We would therefore encourage GPs to introduce this succinct yet comprehensive questionnaire to their practice as part of a foot risk assessment, as it allows identification of the patients' views and misperceptions about foot complications, which could be attended to during medical consultation. Copies of the PIN can be obtained by logging onto www.dialex.org.

\section{Loretta Vileikyte,}

University of Manchester, Manchester, UK. E-mail: LVileikyte@med.miami.edu

Richard R Rubin, Johns Hopkins University, Baltimore, US.

\section{Mark Peyrot,}

Loyola College and Johns Hopkins

University, Baltimore, US.

Jeffrey S Gonzalez,

Yeshiva University, New York, US.

Andrew JM Boulton,

University of Manchester, Manchester, UK.

\section{Jan S Ulbrecht,}

Penn State University, State College, US.

\section{Peter R Cavanagh,}

The University of Washington, Seattle, US.

\section{REFERENCES}

1. Gale L, Vedhara K, Searle A, et al. Patients' perspectives on foot complications in type 2 diabetes: a qualitative study. Br J Gen Pract 2008; 58(553): 555-563.

2. Vileikyte L. Psychological aspects of diabetic peripheral neuropathy. Diabetes Review 1999; 7: 387-394.

3. Vileikyte L, Rubin RR, Leventhal H. Psychological aspects of diabetic neuropathy and its late sequelae. Diabetes Metab Res Rev 2004; suppl 1: S13-18.

4. Vileikyte L, Gonzalez JS, Leventhal $\mathrm{H}$, et al. Patient Interpretation of Neuropathy (PIN) questionnaire: an instrument for assessment of cognitive and emotional factors associated with foot self-care. Diabetes Care 2006; 29(12): 2617-2624.

5. Vileikyte L. Psychosocial and behavioral aspects of diabetic foot lesions. Curr Diab Rep 2008; 8(2): 119-125.

DOI: 10.3399/bjgp09X420383

\section{Palestine}

I am bemused on two counts as to why the BJGP chose to publish Lesley Morrison's essay - Stories from 